\title{
Yatay Borularda Türbülatörlerin Isı Transferine Olan Etkisinin Deneysel Araştırılması
}

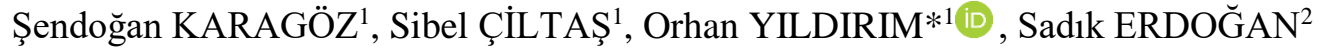 \\ ${ }^{1}$ Atatürk Üniversitesi, Mühendislik Fakültesi, Makine Mühendisliği, Erzurum, Türkiye \\ ${ }^{2}$ Atatürk Üniversitesi, Erzurum Meslek Yüksekokulu, Makine Programı, Erzurum, Türkiye
}

Geliş / Received: 14/09/2018, Kabul / Accepted: 04/02/2019

\begin{abstract}
$\ddot{O} \mathbf{z}$
Bu çalışmada, boru içerisine türbülans oluşturacak kanatçıklar yerleştirilerek boş boru ile kıyaslanmıştır. Üç farklı kanatçık arası mesafede $\left(\mathrm{S}_{\mathrm{y}}=101,216,340\right)$ ve üç farklı kanatçık açısına $\left(\alpha=0^{\circ}, 45^{\circ}, 90^{\circ}\right)$ sahip 9 türbülatör, üç farklı Reynolds sayısında (Re) kullanılmıştır. Bu türbülatörlerin 1Sı transfer performansı ve sürtünme karakteristikleri deneysel olarak incelenmiştir. En yüksek hız değerinde Nu sayısındaki en yüksek artış $\mathrm{S}_{\mathrm{y}}=101 \mathrm{~mm}$ kanatçık arası mesafede ve $\alpha=90^{\circ}$ kanatçık açısında elde edilmiştir. Kanatçık arası mesafenin artmasıyla $\mathrm{Nu}$ sayısında azalma olduğu görülmüştür. $\mathrm{S}_{\mathrm{y}}$ mesafesi en az olan türbülatör bütün $\mathrm{Re}$ sayılarında en yüksek Nu sayısına sahiptir. Nu sayısı açısından sırama yapıldı̆̆ında; $S_{y(10)}>S_{y(5)}>S_{y(3)}$ olduğu gözlemlenmiştir. Bu türbülatörlerin kanatçık arası mesafesinin $\left(S_{y}\right)$ ve kanatçık açılarının $(\alpha)$, Nu sayısına etkisi olduğu yapılan çalışmalarla görülmüştür.
\end{abstract}

Anahtar Kelimeler: Türbülatör, Sürtünme Faktörü, Isı transferi, Basınç Düşümü, Makro Boru

\section{Experimental Investigation of the Effect of Turbulators on Heat Transfer in Horizontal Pipes}

\begin{abstract}
In this study, vanes that will create turbulance indise the pipe were installed in pipe and compared with empty pipe. Nine different turbulators which are at three different distances between wanes $\left(S_{y}=101,216,340\right)$ and has three different angles of vanes $\left(\alpha=0^{\circ}, 45^{\circ}, 90^{\circ}\right)$ were used in three different Reynold Number $(\operatorname{Re})$. Heat transfer performance and friction characteristics of these turbulators have been investigated experimentally. The highest increase in $\mathrm{Nu}$ number in maximum speed value was obtained as $\mathrm{Sy}=101 \mathrm{~mm}$ at vanes distance, and $\alpha=90$ at vanes angle. A decrease in the Nu number was observed with the increase in the distance between the vanes. When the order is made in terms of Nu number; The sequence is $S_{y(10)}>S_{y(5)}>S_{y(3)}$. It was observed in the studies conducted that vane distances (Sy) and vane angles $(\alpha)$ had impact on Nu number.
\end{abstract}

Keywords: Turbulator, Friction Factor, Heat Transfer, Pressure Drop, Macro Pipe

\section{Giriș}

Günümüzde sanayinin ve halkın günlük yaşantısında önemli bir hâle gelen enerjiye talep sürekli artarken enerji kaynakları da hızla tükenmektedir. Kaynakların verimli olarak kullanılması bazı bilim dallarına konu olmaktadır. Soğutma ve 1sıtma sistemlerinde 1S1 geçişinin sağlanabilmesi için yüzey alanının artırılması kullanılan yöntemlerden biridir. Endüstriyel tip kazanlarda, kalorifer tipi kazanlarda, nükleer tesisler verimin artırılması için türbülatör kullanımı oldukça yaygındır. Enerji maliyetini düşürmesi açısından faydalı olan türbülatörlerin tasarımı konusunda çalışmalar yapılmaktadır. Yapılan çalışmalar en uygun türbülatör tipini belirlemek için hem deneysel hem de sayısal olarak yapılmaktadir. Yildız $v d$. (1998) yaptığı çalışmada iç içe çift borulu bir 1s1 değiştiricisine yerleştirilen kıvrımlı şeridin 1S1 transferi ve basınç kaybına olan etkisini belirlemek için çalışmışlardır. Deneyler paralel akış ve zit yönlü akış durumları için yapılmıştır. Çift borulu hava soğutmalı sistemde 1S1 transferi, tüp içerisine yerleştirilen türbülatör sayesinde $\% 100$ artmıştır. Araştırmacılar farklı şekilde tasarlanan türbülatörlerin etkilerini 
gözlemlemek için çalışmalar yürütmüştür. Boru içerisindeki akış da dairesel kesitli helisel yay kullanımının ısı geçişi üzerindeki etkilerini belirlemek için yapılmıştır. $\mathrm{Bu}$ türbülatörlerin, sürtünme faktörü ve Nusselt( $\mathrm{Nu})$ sayısının 1s1 geçişine etkisini incelemişlerdir. Sonuç olarak tel sargıların termodinamik olarak Reynolds(Re) sayısının 13000'e kadar olan değerlerinde avantajlı olduğu görülmüştür(Kahraman $v d$., 2008). Is1 değiştiricilerinde 1s1 geçiş miktarının artışı için kullanılan konik halka türbülatörlerin akışkan titreşim karakteristiklerini, deneysel olarak araştırılmıştır. Re sayısının artışıyla $\mathrm{Nu}$ sayısının artması ve en küçük eğim düzenlemesi için, maksimum 1s1 geçiş miktarı elde edilmiştir(Yakut ve Şahin, 2004). Bir boru içindeki türbülanslı hava akışındaki girdabın etkisi bir diğer araştırma konusu olmuştur. Girdap olmayan borudaki 1S1 transferi ile karşılaştırdıklarında girdap eleman içeren borulardaki 1sı transferinin önemli oranda arttı̆̆1 gözlemlenmiştir (Sparrow et al., 1984).Helisel bantların etkisi olan bir tüpteki 1sı geçiş miktarının artışı bir diğer çalışma konusu olarak karşımıza çıkmaktadır. Tüpün içerisine ısı geçiş oranını artırmaya yardımcı olan girdaplı akış üreten bir helisel bant yerleştirmişlerdir. Re sayısının 2300-8800 arasında değişen akış rejiminde kullanılmıştır. Deneyler sonucunda helisel bantlar kullanmanın düz tüpe göre 1s1 geçiş oranını artırdığı görülmüştür. Düzenli yerleştirilen helisel bantlarda düz tüpe göre $\% 50$ den fazla, s=0,5 de ise en yüksek $\mathrm{Nu}$ sayısı elde edilmiştir (Eimsa-ard and Promvonge, 2005). Is1 transferine etki eden bu türbülatörlerin 1sı geçişini incelemek için sayısal çalışmalar da yapılmaktadır. Bir yüzeyine iki veya üç boyutlu elemanlar yerleştirilen yatay kanaldaki 1sı ve akış özellikleri araştırılmıştır. Sayısal olarak yapılan çalışmada sabit 1sı akısında CFD modeli kullanılarak yapılmıştır. Kullanılan elemanların 1S1 transferini iyileştirdiği görülmüş ve uygulanan modellerin doğruluğu tespit edilmiştir (Karagöz $v d$. 2017; Karagöz., 2015). Arguhan ve Yıldiz (2006) iç içe borulu 1sı değiştiricilerinde içteki borunun döndürülmesiyle dönmenin $\mathrm{Nu}$ Sayısı ve basınç düşüşüne etkisini araştırmışlardır. Dönel helisel iç borunun $\mathrm{Nu}$ sayıs1, dönmeyen düzgün yüzeyli borunun $\mathrm{Nu}$ Sayısının birkaç kat olduğunu gözlemlemişlerdir ve ek basınç düşüşünün 1s1 transferindeki artışı yanında daha düşük kaldığını belirlemişlerdir. Chen $v d$. (2006) çalışmalarında dairesel ve farklı oval kesitli borunun kesit değişimlerinin 1sı transferine etkilerini incelemişlerdir. Laminer akış şartlarında, HAD kodlu bir programda üç farklı geometri modellenerek Reynolds sayısının 500-2000 aralığında 1s1 transfer performansina ve sürtünme faktörüne etkilerini incelenmişlerdir. Reynolds sayısının bu geniş aralığında geometriler optimize edilirse oval kesitli boruların aynı şartlarda dairesel boruya göre daha iyi sonuçlar vereceğini görmüşlerdir. Ho et al. (2005) çoklu geçişli ters akış prensibine göre çalışan güneş enerjili hava 1sıtıcıların performanslarını geliştirmek için çalışmalar yapmıştır. Absorbant plaka ve yalıtım levhası yatay ve dikey olarak yerleştirilerek açık kanallar dört alt kanala ayrılmıştır. Çalışma sayısal olarak gerçekleştirilmiştir. Eklenen plakaların 1S1 geçiş miktarını arttırdığı görülmüştür. Uğurlubilek $v d$. (2011) $18 \mathrm{~mm}$ çaplı bir bakır boruda sıkı geçme olarak helisel türbülatörün 1S1 transferine etkilerini sayısal olarak incelemişlerdir. Re sayısı aralığ1 1000-20000 olarak alınmıştır. Boru boyu $250 \mathrm{~mm}$ et kalınlığ $1 \mathrm{~mm}$ 'dir. Sarım sayıları ise 5, 10, 20 olarak kabul edilmiştir. $\mathrm{Nu}$ değeri, Re sayısına bağlı olarak mevcut kolerasyonlarla kıyaslanmıştır. Helisel türbülatörler laminerin akışta 1S1 geçişini arttırdığı türbülanslı akışta ise verimli olmadığı gözlenmiştir. Bu makalede yatay borularda türbülatörlerin 1S1 transferine olan etkileri deneysel olarak incelenmiş ve $\mathrm{Nu}-\mathrm{Re}$ ve f-Re grafikleri elde edilmiş, farklı 1sı 
transfer iyileştirme elemanlarının kullanıldığ 1 bu çalışmada 1S1 transfer iyileştirmesinin etkisi araştırılarak sonuçlar sunulmuştur.

\section{Materyal ve Metot}

\subsection{Deney düzeneği}

Sistemde bulunan tüm elemanların ve ölçme elemanlarının çalışır durumda olmasının test edildiği ve ölçüm elemanlarının kalibresinin yapıldı ğı deney düzeneği (Şekil 1) akışkan besleme bölümü ve test bölümü olmak üzere iki bölümden oluşmaktadır.

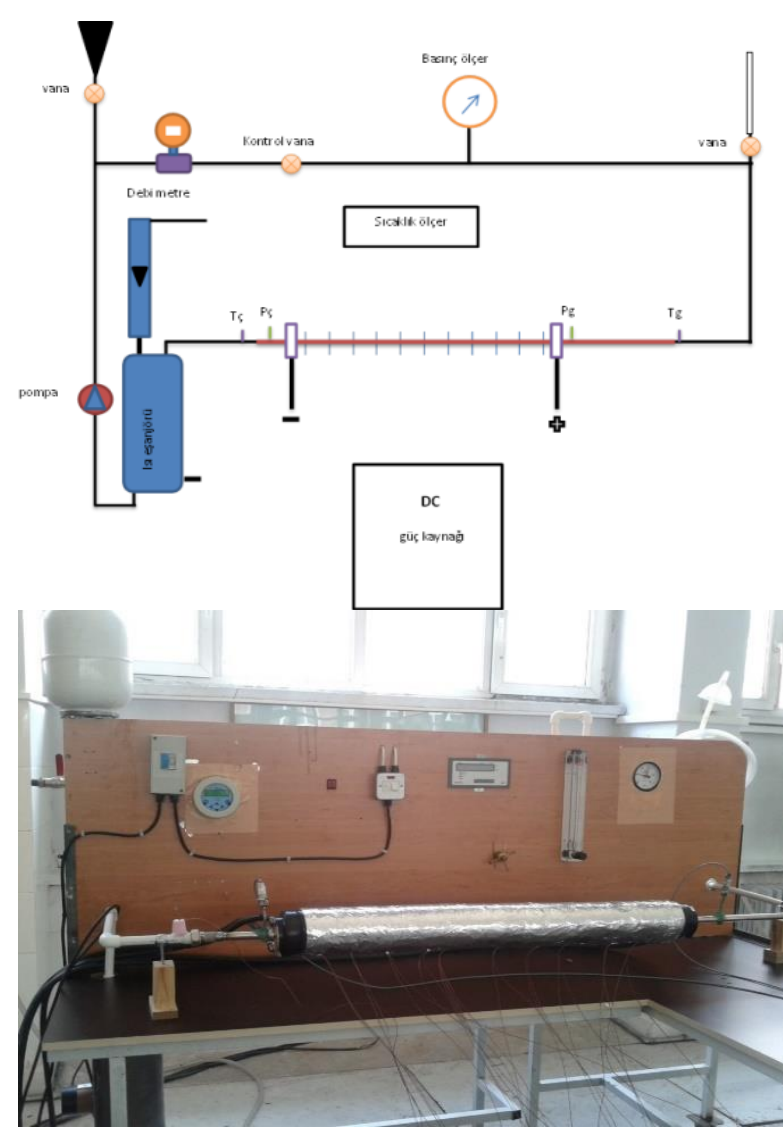

Şekil 1. Deney düzeneğinin fotoğrafi ve şematik görünümü

\subsubsection{Akışkan besleme bölümü}

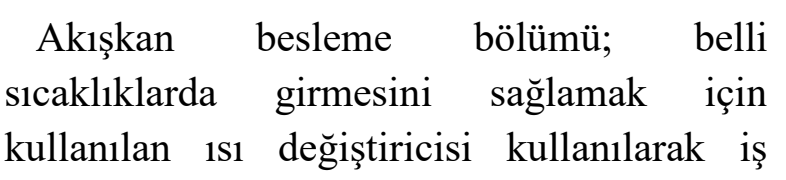

yapan akışkan suyun test borusuna giriş koşullarına getirilmesini sağlamaktadır.

\subsubsection{Test bölümü}

Test bölümü 1sı transferinin meydana geldiği kısımdır. Test borusu kısmında basınç ve sıcaklık ölçüm elemanı bulunmaktadır. Bourdon tipi manometre sistem basincinı ölçmektedir. Sistemin giriş ve çıkışında kullanılan basınç transdüseri basınç kayıplarını ölçmek amacıyla kullanılmıştır. Deneysel çalışmalarda üç farklı debi değeri kullanılmıştır (205-409-614 L/h). İş yapan akışkanın giriş sıcaklığı test bölümüne girmeden önce termoeleman ile ölçülmüştür.

Test borusu boyu $1020 \mathrm{~mm}$, dış çap1 17 $\mathrm{mm}$ ve iç çapı 13,5 mm olan $\mathrm{Cr}-\mathrm{Ni}$ (316L) bir borudur. Test borusu cidarına termoelemanların 11 tanesi üst cidara diğer 11 tanesi de alt cidara olmak üzere eşit aralıklarla yerleştirilmiş, test borusunun giriş ve çıkış sıcaklıklarını ölçmek amacıyla da 2 adet T-tipi bakır-konstant termoelemanlar kullanılmıştır.

\subsection{Deneysel yöntem}

Deneysel çalışmalar 614 - 409 - 205 L/h aralığında debi, 10 - 5-3 kanatçık sayılarına sahip elemanlarla gerçekleştirilmiştir. 


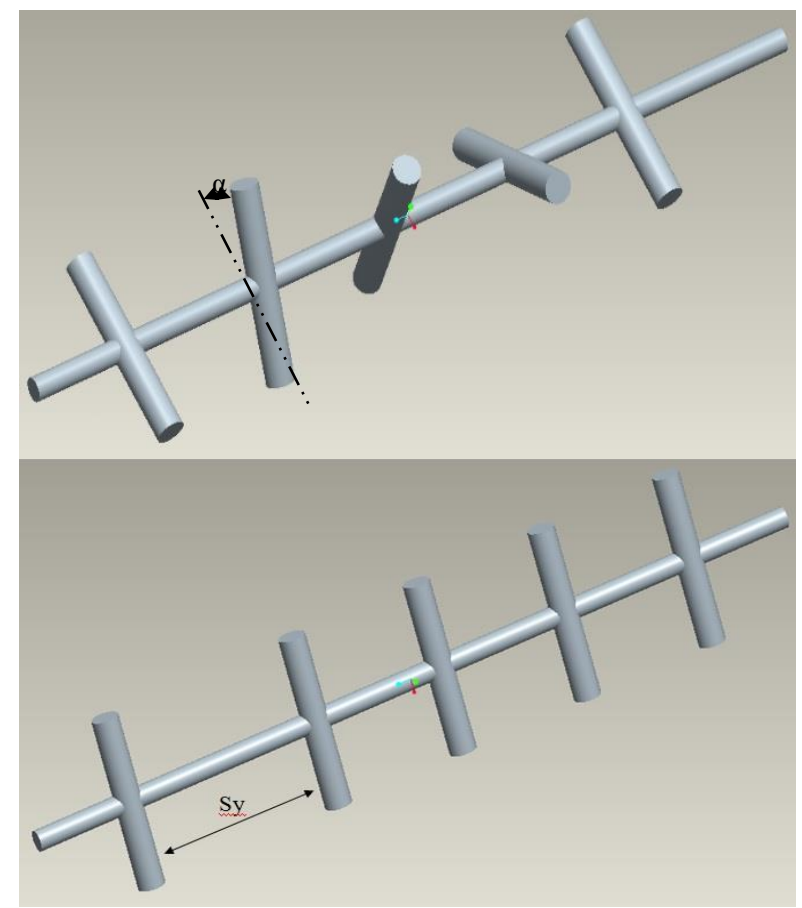

Şekil 2. $0^{\circ}$ de sabitlenmiş ve farklı açılarda sabitlenen türbülatörler

Çizelge 1'de gösterildiği gibi 1sı transfer yüzeyleri efektif çapla karakterize edilmektedir. Efektif çap aşağıdaki eşitlik kullanılarak hesaplanmıştır.

$$
\mathrm{d}_{\mathrm{e}}=\sqrt{\frac{4 \mathrm{~V}^{\prime}}{\pi \mathrm{L}}}
$$

Burada $\mathrm{V}^{\prime}\left(V^{\prime}=V_{\text {boru }}-V_{\text {Türbülatör }}\right)$ boru net iç hacmini ve $\mathrm{L}$ boru uzunluğunu belirtmektedir.

Çizelge 1. Is1 transfer yüzey konfigürasyonları ve karakteristikleri

\begin{tabular}{|l|l|}
\hline Borunun karakteristiği & De $(\mathrm{mm})$ \\
\hline Boş boru & 13,50 \\
\hline 3 elemanlı boru & 13,48 \\
\hline 5 elemanlı boru & 13,47 \\
\hline 10 elemanlı boru & 13,45 \\
\hline
\end{tabular}

Çizelge 2. Deneysel parametreler

\begin{tabular}{|l|l|l|l|}
\hline $\mathrm{S}_{\mathrm{y}}(\mathrm{mm})$ & 101 & 216 & 340 \\
\hline$\alpha\left({ }^{\circ}\right)$ & 0 & 45 & 90 \\
\hline $\operatorname{Re}$ & 6000 & 12000 & 18000 \\
\hline
\end{tabular}

Deneysel sistemin kurulmasiyla ilgili çalışmalar şu şekilde özetlenebilir: i. Sistemde test borusu olarak $1020 \mathrm{~mm}$ uzunluğunda, $13,5 \mathrm{~mm}$ çapında $\mathrm{Cr}-\mathrm{Ni}$ (paslanmaz çelik 316L) malzemeden yapılmış çelik bir boru kullanılmıştır.

ii. Dengeleyici tank gerekli çalışma basınçlarına dayanıklı malzemeden üretilmiştir.

iii. Güç kaynağı, ssıtıcı test borusunda ihtiyaç duyulan 1 sıl enerjiyi sağlamak için kullanılmaktadır. (DC güç kaynağından ölçülen akım değeri; 1,8 Watt, 210A)

$i v$. Sistemde gerekli test basıncını sağlamak için basınçlı el cenderesi kullanılmıştır. Basınç farkını ölçmek için giriş ve çıkış bölgesinde birer tane basınçölçer kullanılmıştır.

v. Sisteme giren akışkanın debi ölçümleri için türbin tipi debi ölçer kullanılmıştır.

vi. Termoelemanlar, basınç transdüseri ve türbin tipi debi ölçerden alınan veriler data logger vasıtasıyla bilgisayara aktarılmıştır. Toplam 24 adet termoeleman kullanılmıştır.

vii. Sistemde iş yapan akışkan suyu dolaştırmak amacıyla bir adet pompa kullanılmıştır.

viii. Test borusunda istenilen sıcaklıkta iş yapan akışkan girişini sağlamak amacıyla bir adet 1Sı değiştiricisi kullanılmıştır.

\subsection{Hesaplama metodu}

Elde edilen deneysel veriler kullanılarak Nusselt Sayısı (Nu), sürtünme faktörü (f) ve Reynolds Sayısı (Re) hesaplanmıştır.

Buna göre sisteme verilen 1s1, DC güç kaynağının volt ve akımı direkt olarak okunmuştur. Güç kaynağından alınan 1S1 akışkana aktarılırken kayıplar oluşmuştur. $\mathrm{Bu}$ kayıpları önlemek ve hesaba katmak için $\sqrt{3}$ katsayısı ile çarpılmıştır. Buradan da sisteme verilen 1s1 miktar1;

$$
Q=V I \sqrt{3}
$$

Yüzeyden akışkana aktarılan 1sı;

$$
Q=h A(T w-T s)
$$


Burada A borunun iç yüzey alanı, $\mathrm{T}_{\mathrm{s}}$, suyun ortalama sicaklığg olup $\left(\left(T_{g}+T_{c}\right) / 2\right)$ şeklinde ifade edilir. $\mathrm{T}_{\mathrm{w}}$ ise borunun ortalama cidar sıcaklığıdır. $\mathrm{Bu}$ ifadeden elde edilen 1s1 taşınım katsayısı yardımıyla Nu Sayısı;

$$
N u=\frac{h D}{k}
$$

İfadesiyle belirlenir, burada D borunun iç çapı, $\mathrm{k}$ ise suyun 1 sı iletim katsayısıdır. Darcy sürtünme faktörü $(f)$ pratik olarak şu şekilde ifade edilmiștir;

$$
\Delta P=f \frac{L}{D}\left(\frac{1}{2} \rho V^{2}\right)
$$

Re Sayısı da aşağıdaki bağıntı yardımıyla bulunur;

$$
\operatorname{Re}=\frac{\rho V D}{\mu}
$$

Burada V karakteristik sıvı hızı, D borunun iç çapı, $\mu \quad$ sıv1 viskozitesi, $\rho$ sıv1 yoğunluğudur.

\section{Bulgular}

$\mathrm{Bu}$ bölümde deneysel çalışmalarda edilen araştırma bulguları değerlendirilmiş sonuçlar grafiksel ortamda hazırlanmıştır. Sonuçlar boş borudaki akış ve iyileştirme elemanı kullanan borulardaki akış olmak üzere iki alt bölüm hâlinde incelenmiştir.

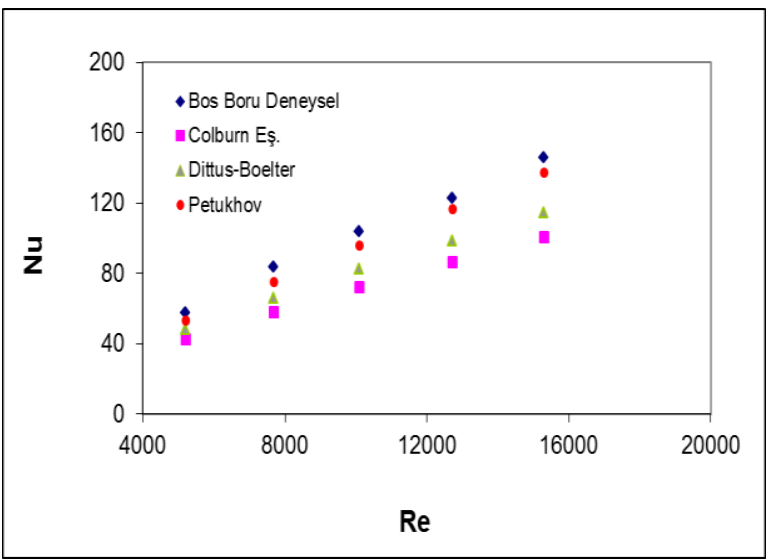

Şekil 3. Boş boru için Nu- Re değişimi

\subsection{Boș boruda akıș}

Şekil 3'te Boş Boru'da yapılan deneysel sonuçlar görülmektedir. Şekil 3'ten de anlaşılacağı gibi elde edilen sonuçlar literatürde verilen sonuçlarla uyum içerisindedir. Borunun farklı çalışma debilerinde ölçülen yüzey sıcaklık ortalaması ve giriş-çıkış sicaklık ortalamasının değişmesine 1S1 taşınım katsayısı(h) etki etmektedir. Re sayısının artması ile $\mathrm{Nu}$ sayısının artması beklenen bir sonuçtur. Deneysel çalışma koşulları için elde edilen $\mathrm{Nu}$ say1s1 korelasyonu $\mathrm{Nu}=0,0112 \cdot \mathrm{Re}^{0,8427} \mathrm{Pr}$ (1/3) şeklindedir. Re sayısı aralığ 1 ise 600018000 olarak belirlenmiştir. Bu korelasyon aşağıda verilen korelasyonla karşılaştırıldığında mühendislik açısından uygun bir korelasyon olduğu anlaşılmaktadır.

Colburn denklemi: $\quad \mathrm{Nu}=0,023 \cdot \operatorname{Re}^{0,8} \cdot \operatorname{Pr}^{1 / 3}$ Dittus-Boelter denklemi: $\mathrm{Nu}=0,023 \cdot \operatorname{Re}^{0,8} \cdot \operatorname{Pr}^{\mathrm{n}}$ $(\mathrm{n}=0,4 / 0,3)$

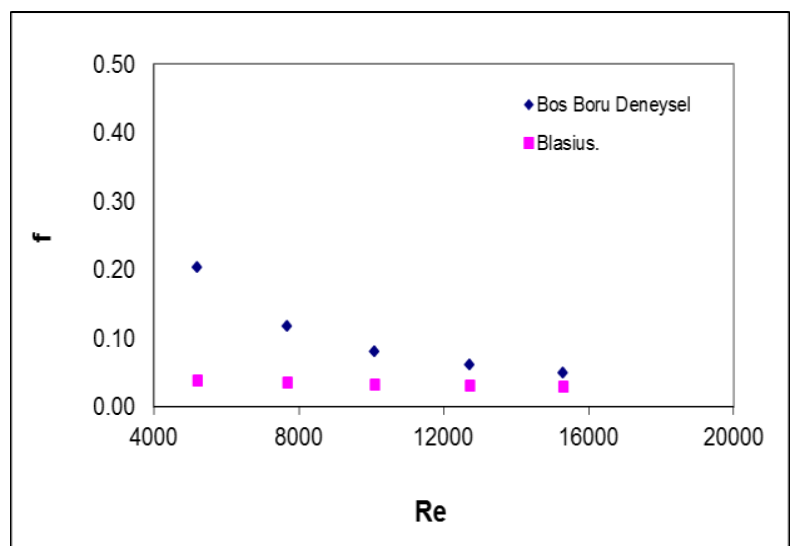

Şekil 4. Boş boru için f- Re değişimi

Şekil 4'te Boș Boru'da yapılan deneysel sonuçlar gösterilmiştir. Şekil 4.'dan da anlaşılacağı gibi f-Re ilişkisi literatürdeki sonuçlarla uygunluk göstermektedir. Re sayısının artması ile f'nin azalması beklenen bir sonuçtur. Şekil 4'de ilk değerlerin yüksek olduğu görülmektedir. Bunun nedeni basınç düșümü değerlerinin düșük hızlarda hassas olarak okunamamasindan kaynaklanmaktadır. Ayrıca Blasius eșitliğinde hassasiyetin \%25 olduğu düşünülürse bu hata düzeyinin beklenmesi normaldir. Deneysel çalışma koşulları için elde edilen $\mathrm{f}$ sayıs korelasyonu $\mathrm{f}=15433$. Re ${ }^{-1,334}$ șekilindedir. 
Blasius denklemi: $\quad \mathrm{f}=0,316 \cdot \mathrm{Re}^{-0,25}$

\subsection{Türbülatörlü borularda akıș}

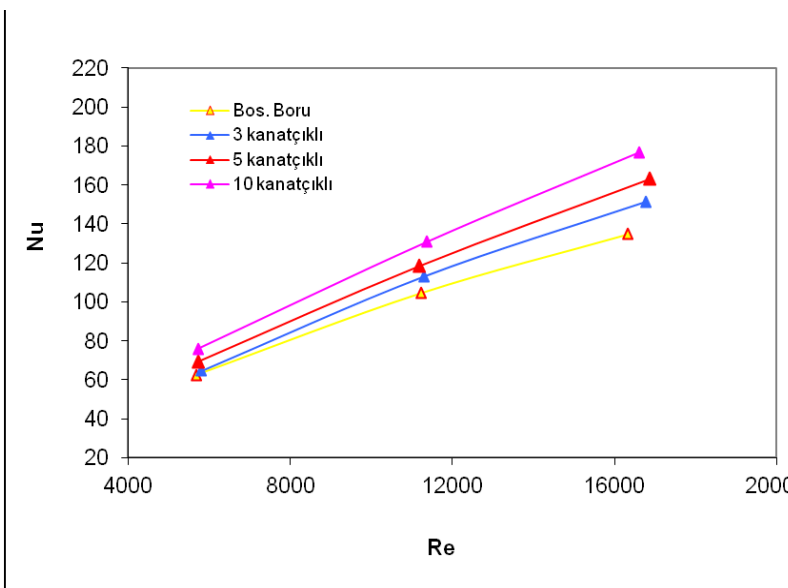

Şekil 5. 3,5 ve 10 kanatçıklı türbülatörlerin $45^{\circ}$ de $\mathrm{Nu}-\mathrm{Re}$ değişimi

Şekil 5 'da görüldüğü gibi boru içerisine $45^{\circ}$ açıda ve üç farklı kanatçıklar arası mesafeye $\left(S_{y}\right)$ sahip türbülatörler için $\mathrm{Nu}-\mathrm{Re}$ değişimi gösterilmektedir. $\mathrm{S}_{\mathrm{y}}$ mesafesi en az olan türbülatör için artan $\mathrm{Re}$ sayılarıyla $\mathrm{Nu}$ sayıları da artmaktadır. Nu sayısı açısından sirama yapıldığında $\mathrm{Nu}{ }_{10}>\mathrm{Nu}_{5}>\mathrm{Nu}_{3}$ olduğu görülmektedir. Bütün türbülatörler Boş Boru ile karşılaştırıldığında artan Re sayılarıyla beraber $\mathrm{Nu}$ sayılarında da belirgin bir artış görülmektedir. Sy'nin azalmasıyla kanatçık sayıs1 artmakta ve $\mathrm{Nu}$ sayıs1 artmaktadır (Eiamsa-ard. et al., 2010).

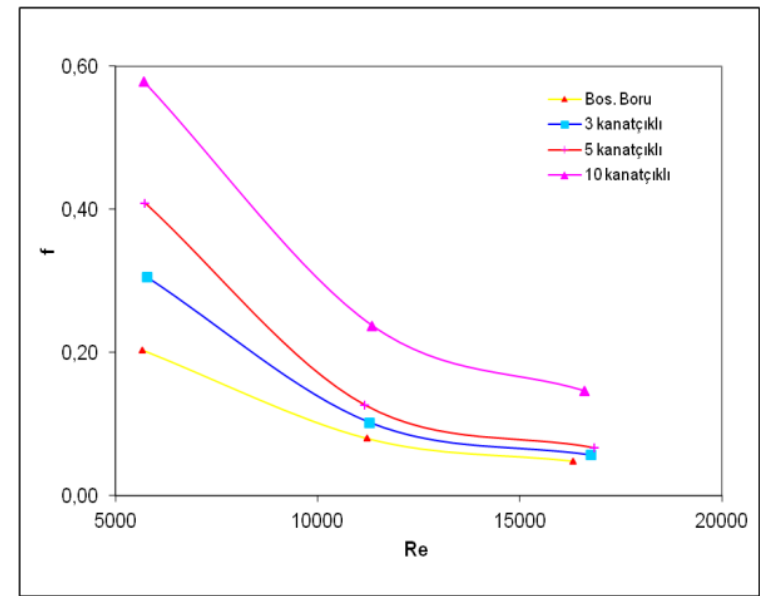

Şekil 6. 3,5 ve 10 kanatçıklı türbülatörlerin $45^{\circ}$ de f-Re sayısı değişimi

Şekil 6'de görüldüğü gibi boru içerisine $45^{\circ}$ açıda üç farklı kanatçıklar arası mesafeye
(Sy) sahip türbülatörler yerleştirilmesi sonucu elde edilen sürtünme katsayısının Re ile değişimi görülmektedir. Yerleştirilen her bir türbülatör Boş Boru ile karşılaştırıldığında sürtünme katsayısında belirli bir artış gözlenmiştir. Sy mesafesi en az olan türbülatör bütün $\mathrm{Re}$ sayılarında en yüksek sürtünme katsayısına sahiptir. f sayısı açısından sıralama yapıldı ğında $\mathrm{f}_{10}>\mathrm{f}_{5}>\mathrm{f}_{3}$ olduğu görülmektedir. $\mathrm{Bu}$ da $\mathrm{S}_{\mathrm{y}}$ 'nin azalması kanatçık sayısını artırmakta ve f'nin artmasına sebep olmaktadır (Eiamsa-ard. et al., 2010).

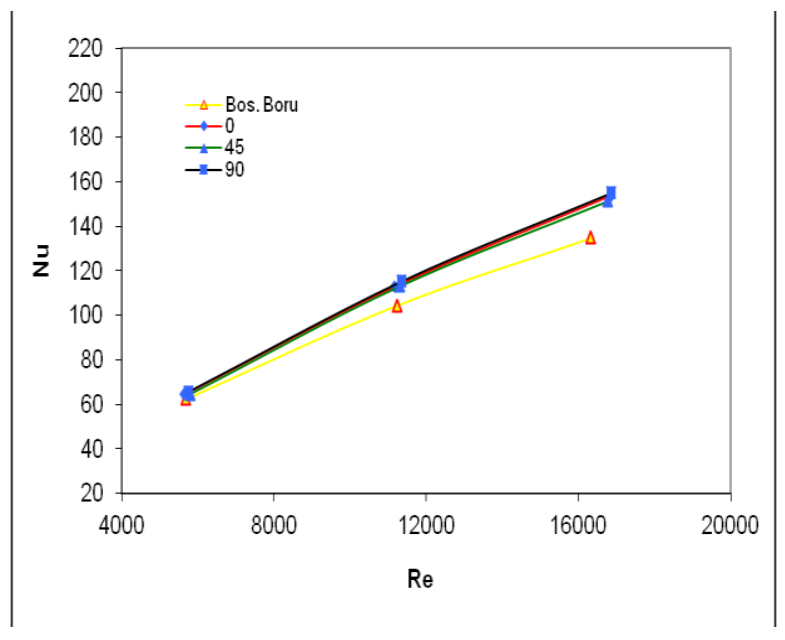

Şekil 7. Üç kanatçıklı $0^{\circ}, 45^{\circ}, 90^{\circ}$ açılarına sahip türbülatörlerin $\mathrm{Nu}$ - Re değişimi

Şekil 7'de görüldüğü gibi boru içerisine aynı $\mathrm{S}_{y}$ kanatçık mesafesinde ve üç farklı açılara $(\alpha)$ sahip türbülatörler için $\mathrm{Nu}-\mathrm{Re}$ değişimi görülmektedir. Bütün türbülatörler Boş Boru ile karşılaştırıldığında artan Re sayıları ile beraber $\mathrm{Nu}$ sayılarında da belirgin bir artıș söz konusudur. $\alpha$ açısı en büyük olan türbülatör bütün $\mathrm{Re}$ sayılarında en yüksek $\mathrm{Nu}$ sayısı elde edilmiştir. $\mathrm{Nu}$ sayısı açısından sıralama yapıldığında $90^{\circ}>0^{\circ}>45^{\circ}$ olduğu görülmektedir. Bu durum, kanatçıkların boru içindeki konumu ile açıklanabilir. Normalde beklenen açı sıralaması küçükten büyüğe doğrudur (Yıldız vd., 2002). Yatay akışta yerçekimi kuvvetleri akışkan akışına dik yönde sıvı yoğunluklarına bağlı olarak etki yapar. $\mathrm{Bu}$ ise asimetrik yoğunluk farkına ve ayrışmaya neden olur. $\mathrm{Bu}$ kuvvetler, yoğunluğu yüksek olan sıvıyı boru tabanına, düşük olan sıvıyı borunun üst tarafına doğru yönlendirir (Sekmen, 2006). Bu da boru 
içerisindeki iş yapan akışkanın alt cidar yakınlarında daha düşük sıcaklıklarda üst cidara yakın akışkanın ise daha yüksek sıcaklıklarda olması anlamına gelir. Düşük sıcaklıktaki akışkan cidarda daha fazla 1s1 absorbe etme eğilimindedir. Dolayısıyla boru içerisine yerleştirilecek türbülatörün konumu bu açıdan önem kazanmaktadır.

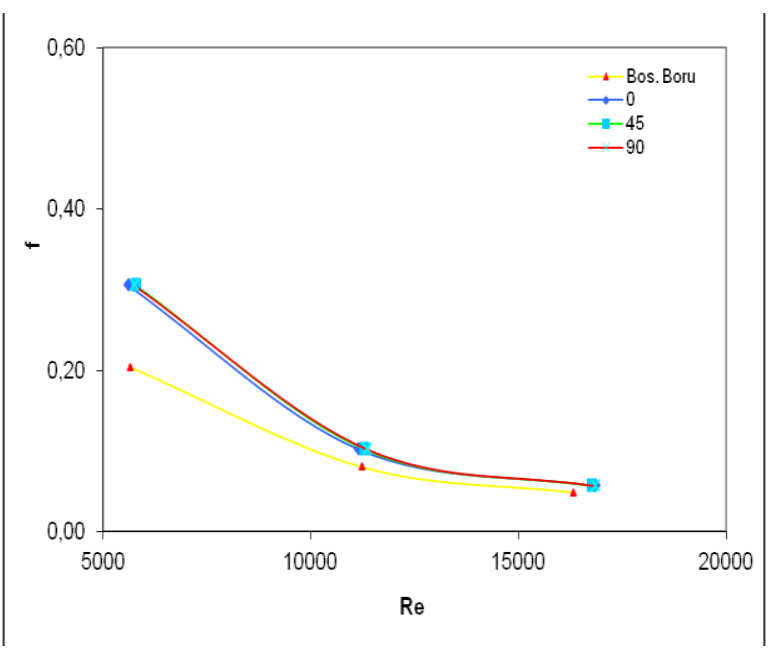

Şekil 8. Üç kanatçıklı $0^{\circ}, 45^{\circ}, 90^{\circ}$ açılarına sahip türbülatörlerin f-Re sayısı değişimi

Şekil 8'da görüldüğü gibi boru içerisine aynı $S_{y}$ mesafede ve üç farklı açılara $\left(\alpha=0^{\circ}\right.$ $, 45^{\circ}, 90^{\circ}$ ) sahip türbülatörler yerleştirilmesi sonucu elde edilen sürtünme katsayısının $\mathrm{Re}$ ile değişimi görülmektedir. Yerleştirilen her bir türbülatör Boş Boru ile karşılaştırıldığında sürtünme katsayısında belirli bir artıș elde edilmiștir. Türbülatörler kendi aralarında belirgin bir etki göstermemiştir. Bunun nedeni efektif çapın sabit kalması, yani kanatçık adedinin sabit olmasıyla açıklanabilir.

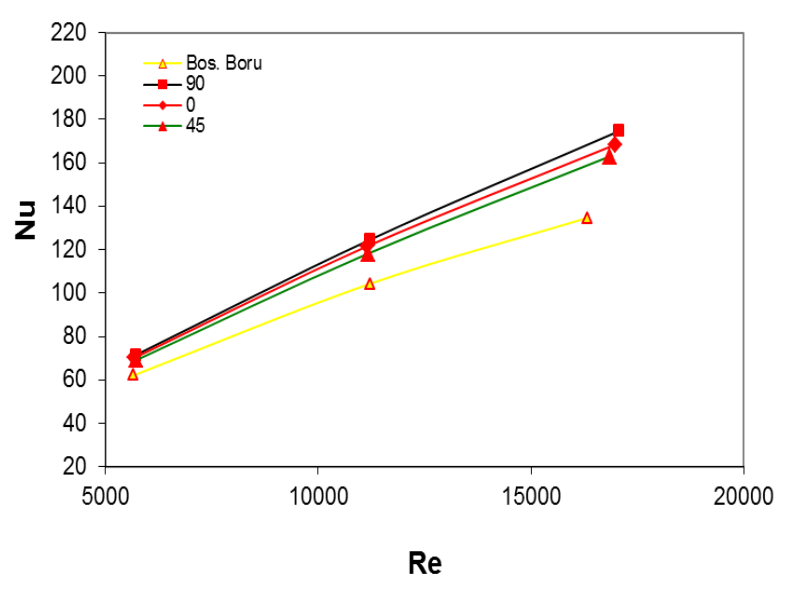

Şekil 9. Beş kanatçıklı $0^{\circ}, 45^{\circ}, 90^{\circ}$ açılarına sahip türbülatörlerin $\mathrm{Nu}-\mathrm{Re}$ değişimi

Şekil 9'da görüldüğü gibi boru içerisine aynı $\mathrm{S}_{y}$ mesafede ve üç farklı açılara $(\alpha)$ sahip türbülatörler için $\mathrm{Nu}-\mathrm{Re}$ değişimi gösterilmiştir. Bütün türbülatörler Boş Boru ile karşılaştırıldığında yüksek Re sayılarında $\mathrm{Nu}$ sayısında belirgin bir artış vardır. $\alpha$ açısı en büyük olan türbülatör bütün $\mathrm{Re}$ sayılarında en yüksek $\mathrm{Nu}$ sayısına sahiptir. $\mathrm{Nu}$ sayısı açısından sıralama yapıldığında $90^{\circ}>0^{\circ}>45^{\circ}$ olduğu görülmektedir. Bunu, kanatçıkların boru içindeki konumu ile açıklayabiliriz. Normalde beklenen açı sıralaması küçükten büyüğe doğrudur (Sekmen, 2006). Yatay akışta yerçekimi kuvvetleri akışkan akışına dik yönde sıvı yoğunluklarına bağlı olarak etki yapar. Bu ise asimetrik yoğunluk farkına neden olur ve ayrışmayı oluşturur. Bu kuvvetler, yoğunluğu yüksek olan sıvıyı boru tabanına, düşük olan sıviyı ise borunun üst tarafına doğru yönlendirir (Karagöz et al.,2017; Karagöz, 2015). Bu da boru içerisindeki iş yapan akıșkanın alt cidar yakınlarında daha düşük sıcaklıklarda üst cidara yakın akıșkanın ise daha yüksek sıcaklıklarda olması demektir. Düşük sıcaklıktaki akışkan cidarda daha fazla 1s1 absorbe eder. Bundan dolay1 boru içerisine yerleştirilecek türbülatörün konumu önemli bir mühendislik yaklaşımını ortaya koymaktadır. 


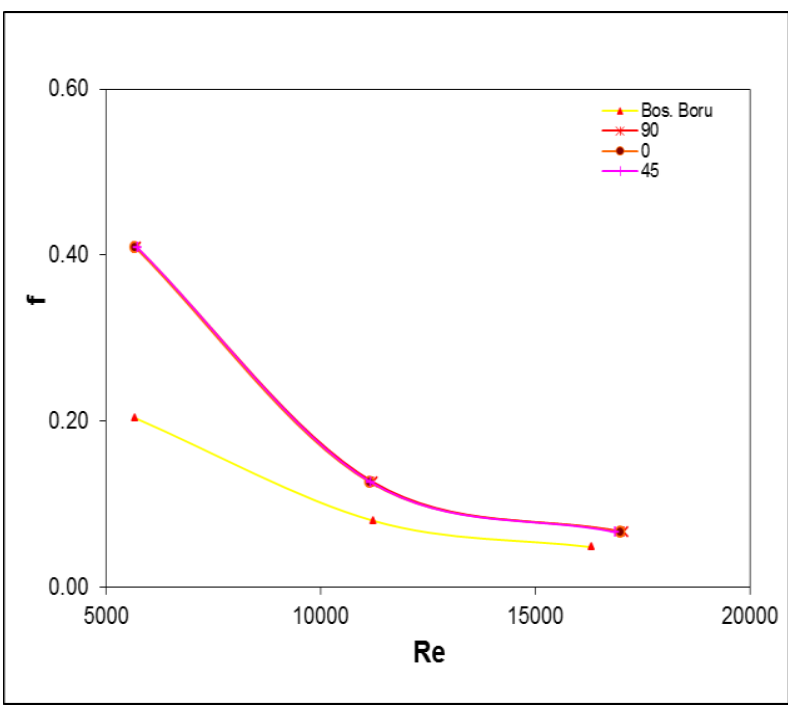

Şekil 10. Beş kanatçıklı $0^{\circ}, 45^{\circ}, 90^{\circ}$ açılarına sahip türbülatörlerin $\mathrm{f}-\mathrm{Re}$ değişimi

Şekil 10'de görüldüğü gibi boru içerisine üç farklı açıya $\left(\alpha=0^{\circ}, 45^{\circ}, 90^{\circ}\right)$ sahip ve aynı $\mathrm{S}_{\mathrm{y}}$ mesafede türbülatörler yerleştirilmesi sonucu elde edilen sürtünme katsayısının $\mathrm{Re}$ ile değişimi görülmektedir. Yerleştirilen her bir türbülatör boş boru ile karşılaştırıldığında sürtünme katsayısında belirli bir artış elde edilmiştir. Türbülatörler kendi aralarında belirgin bir etki göstermemiştir. Bunun nedeni efektif çapın sabit kalması, yani kanatçık adedinin sabit olması ile açıklanabilir.

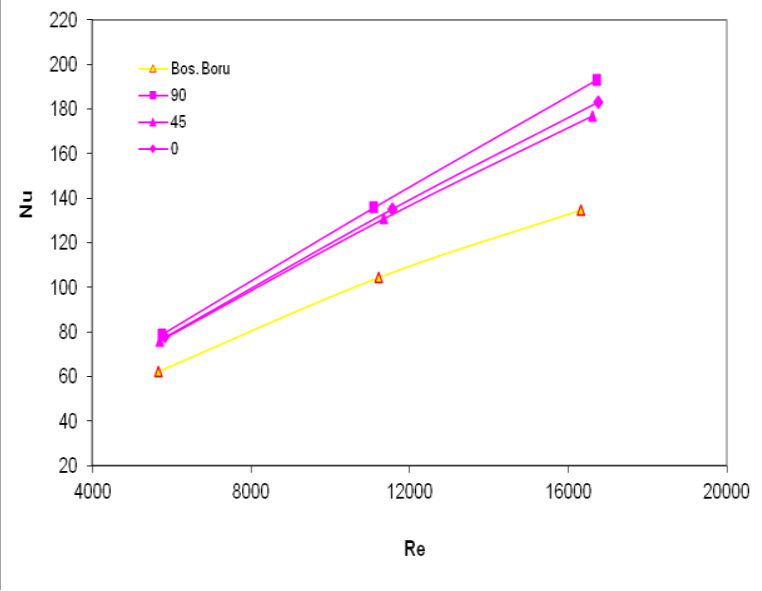

Şekil 11. On kanatçıklı $0^{\circ}, 45^{\circ}, 90^{\circ}$ açılarına sahip türbülatörlerin $\mathrm{Nu}-\mathrm{Re}$ değişimi

Şekil 11'de görüldüğü gibi boru içerisine aynı $\mathrm{S}_{y}$ mesafede ve üç farklı açılara $(\alpha)$ sahip türbülatörler için $\mathrm{Nu}-\mathrm{Re}$ değişimi görülmektedir. Bütün türbülatörler Boş Boru ile karşılaştırıldığında artan Re sayılarıyla beraber $\mathrm{Nu}$ sayılarında belirgin bir artış gözlenmiştir. $\alpha$ açısı en büyük olan türbülatör bütün Re sayılarında en yüksek $\mathrm{Nu}$ sayısına sahiptir. $\mathrm{Nu}$ sayısı açısından sıralama yapıldı ğında $\quad 90^{\circ}>0^{\circ}>45^{\circ} \quad$ olduğu görülmektedir. Bunun nedeni, kanatçıkların boru içindeki konumu ile açıklanabilir. Normalde beklenen açı sıralaması küçükten büyüğe doğrudur (Sekmen, 2006). Yatay akışta yerçekimi kuvvetleri akışkan akışına dik yönde sıvı yoğunluklarına bağlı olarak etki yapar. Bu ise asimetrik yoğunluk farkına neden olur ve ayrışma ortaya çıkar. Bu kuvvetler, yoğunluğu yüksek olan sıvıyı boru tabanına, düşük olan sıvıyı ise borunun üst tarafına doğru yönlendirir (Karagöz et al.,2017; Karagöz, 2015). Bu da boru içerisindeki iş yapan akışkanın alt cidar yakınlarında daha düşük sicaklıklarda üst cidara yakın akışkanın ise daha yüksek sıcaklıklarda olmasına neden olur. Düşük sıcaklıktaki akışkan cidarda daha fazla 1s1 absorbe eder. Bundan dolayı boru içerisine yerleştirilecek türbülatörün konumu mühendislik açısından önemlidir.

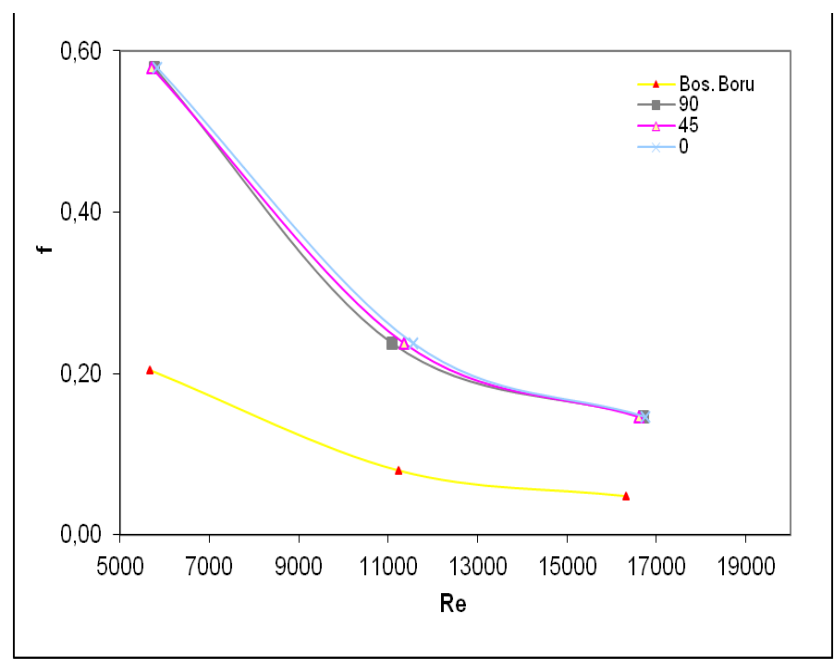

Şekil 12. On kanatçıklı $0^{\circ}, 45^{\circ}, 90^{\circ}$ açılarına sahip türbülatörlerin $\mathrm{f}-\mathrm{Re}$ değişimi

Şekil 12'te görüldüğü gibi boru içerisine aynı $\mathrm{S}_{\mathrm{y}}$ mesafede ve üç farklı açılara $\left(\alpha=0^{\circ}\right.$ $\left., 45^{\circ}, 90^{\circ}\right) \quad$ sahip türbülatörlerin yerleştirilmesi sonucu elde edilen sürtünme katsayısının Re ile değişimi görülmektedir. Yerleştirilen her bir türbülatör Boş Boru ile karşılaştırıldığında sürtünme katsayısında 
belirli bir artışa söz konusudur. Türbülatörler kendi aralarında belirgin bir etki göstermemiştir. Bunun nedeni efektif çapın sabit kalması, yani kanatçık adedinin sabit olması ile açıklanabilir.

\section{Sonuç ve Tartışma}

Bu deneysel çalışmada, boru içerisinde akışta türbülans oluşturacak kanatçıklar yerleştirilmiştir. Üç farklı kanatçıklar arası mesafe $\left(S_{y}\right)$, kanatçık açısı $(\alpha)$ ve Re sayısına $(\mathrm{Re})$ sahip toplam dokuz farklı türbülatör kullanılarak sabit 1s1 akısında $\mathrm{Nu}$ ve $\mathrm{f}$ değerleri incelenmiştir. Sonuçlar aşağıda maddeler hâlinde verilmiştir;

- Deneysel çalışmalarda elde edilen $\mathrm{Nu}$ sayıs1 korelasyonu literatürdeki korelasyonlarla uyum içerisindedir. Re sayısı 6000-18000 olarak belirlenmiştir.

- Boru içerisine üç farklı kanatçıklar arası mesafeye $\left(\mathrm{S}_{\mathrm{y}}\right)$ sahip türbülatörler yerleştirilmiştir. Sy mesafesi en az olan türbülatör bütün Re sayılarında en yüksek $\mathrm{Nu}$ sayısına sahiptir. $\mathrm{Nu}$ sayısı açısından sırama yapıldığında; $S_{\mathrm{y}(10)}>S_{\mathrm{y}(5)}>S_{\mathrm{y}(3)}$ olduğu görülmektedir.

- Deneylerdeki efektif çap azaldıkça $\mathrm{Nu}$ sayısının arttığı görülmüştür. Deneylerdeki efektif çap azaldıkça sürtünme katsayısının arttığı görülmüştür.

- $\mathrm{Bu}$ türbülatörler Boş Boru ile karşılaştırıldığında artan Re sayılarıyla beraber $\mathrm{Nu}$ sayısında da belirgin bir artış gözlenmiştir. Bunun nedeni Sy'nin azalması kanatçık adedinin artması ile açıklanabilir.

- Boru içerisine üç farklı kanatçıklar arası mesafeye $\quad\left(S_{\mathrm{y}}\right)$ sahip türbülatörler yerleştirilmesi sonucu elde edilen sürtünme katsayısı Boş Boru ile karşılaştırıldığında sürtünme katsayısında belirli bir artış söz konusudur.

- Sy mesafesi en az olan türbülatör bütün Re sayılarında en yüksek sürtünme katsayısına sahiptir. Bunun nedeni Sy'nin azalması ile kanatçık adedinin artmasıdır.

- Boru içerisine üç farklı açıya $(\alpha)$ sahip türbülatörler yerleştirilmiştir. $\quad \mathrm{Bu}$ türbülatörler Boş Boru ile karşılaştırıldığında artan Re sayılarıyla beraber $\mathrm{Nu}$ sayısında da belirgin bir artış görülmüştür.
- Boru içerisine üç farklı açıya ( $\alpha$ ) sahip türbülatörler yerleştirilmesi sonucu elde edilen sürtünme katsayısının boş boru ile karşılaştırıldığında sürtünme katsayısında belirli bir artış gözlenmiştir. Türbülatörler kendi aralarında belirgin bir etki göstermemiştir. Bunun nedeni ise efektif çapın sabit kalması, yani kanatçık adedinin sabit olması ile açıklanabilir.

- $\mathrm{Nu}$ sayisina ve sürtünme faktörüne olan etkileri hakkında daha kesin ve detaylı bilgi sahibi olmak için deneylerde incelenen türbülatörlerin kanatçıklar arası mesafeleri $\left(S_{y}\right)$, kanatçık açıları $(\alpha)$ ve Re sayıları $(R e)$ farkl1 kombinasyonlar da deneyler yapmak gerekmektedir.

- Yatay akışta yerçekimi kuvveti akışkan akışına dik yönde sıvı yoğunluklarına bağlı olarak etki yapar. $\mathrm{Bu}$ ise asimetrik yoğunluk farkına ve ayrışmaya neden olur. $\mathrm{Bu}$ kuvvetler yoğunluğu yüksek olan sıvıyı boru tabanına yönlendirirken düşük olan sıvıyı ise borunun üst cidarına yönlendirir. Bu nedenle boru içerisinde iş akışkanın alt cidar yakınlarında düşük sıcaklıklarda üst cidar yakınlarında ise yüksek sıcaklıklarda olması anlamına gelir. $\mathrm{Bu}$ nedenle Türbülatörün konumu önem arz etmektedir.(Karslı, 2000)

- Paket programlarla bu deneylerin teorik çözümlemelerinin yapılması uygun olacaktır.

\section{Teşekkür}

Bu makale Sevin (Sibel) ÇİLTAŞ tarafından hazırlanan yüksek lisans tezinin bir kısmıdır. Makalede bulunan yazarlar Sevin ÇíLTAŞ'a teşekkür etmektedir.

\section{Kaynaklar}

Sevin ÇILTAŞ. 2012. "Yatay Borularda Türbülatörlerin Is1 Transferine Olan Etkisinin Deneysel Araştırılması”, Yüksek Lisans Tezi, Atatürk Üniversitesi. Yıldız, C., Biçer, Y., Pehlivan, D. 1998. Effect of Twisted Strips on Heat Transfer and Pressure Drop in Heat Exchanger, Energy Conversion \& Management, 39, 331-336. 
Tanda, G., 2004. Heat Transfer in Rectangular Channels with Transverse and V-Shaped Broken Ribs, International Journal of Heat and Mass Transfer, 47, 229-243.

Karslı, S., 2000. “Zorlanmış konveksiyonlu kaynamalı yatay bir boru sisteminde iki fazlı akış kararsızlıklarının deneysel olarak incelenmesi”, Doktora Tezi, Atatürk Üniversitesi.

Yakut, K., Sahin, B. 2004. The Effects of Vortex Characteristics on Performance of Coiled Wire Turbulators Used for Heat Transfer Augmentation, Applied Thermal Engineering, 24, 2427-2438.

Sparrow, E.M., Chaboki, A. 1984. Swirl Affected Turbulent Fluid Flow and Heat Transfer in a Circular Tube, ASME Journal of Heat Transfer, 106, 766-773.

Ko, K-H., Anand, N.K. 2003. Use of Porous Baffles to Enhance Heat Transfer in a Rectangular Channel, International Journal of Heat and Mass Transfer, 46, 4191- 4199.

Eiamsa-ard, S. and Promvonge, P. 2005. Enhancement of Heat Transfer in a Tube With Regularly-spaced Helical Tape Swirl Generators, Solar Energy, 78, 483494.

Lee, C.K. ve Abdel-Moneim, S.A. 2001. Computational Analysis of Heat Transfer in Turbulent Flow Past a Horizantal Surface with Two-Dimensional Ribs, Int. Comm. Heat Mass Transfer, 28, 2, 161170.

Argunhan, Z., ve Y1ldiz, Cengiz., 2006. Dairesel Kesitli Bir Borunun Girişine Yerleştirilen Delikli Sabit Kanatçıklı Dönme Üreticinin Isı Geçiși ve Basınç Düşüşüne Etkileri, Pamukkale Universty Engineering College Mühendislik Bilimleri Dergisi, 12 (2), 217-223.

Yıldız C., Çakmak G. 2002. Boru Girisinde Düzgün Siralı Enjektörlü Türbülans Üretici Bulunan Is1 Degistiricilerinde Is1 Geçisinin ve Basınç Düsümünün incelenmesi, Termodinamik Dergisi, 116, 103-110.

Ufuk SEKMEN. 2006. "Boru içi akışlarda türbülatörlerin 1S1 transferine olan etkisinin araştırılması". Yüksek Lisans Tezi. Erciyes Üniversitesi.
Zimparov, V. 2004. Prediction of Friction Factors and Heat Transfer Coefficients For Turbulent Flow in Corrugated Tubes Combined Twisted Tape İnserts. Part 2: Heat Transfer Coefficients, International Journal of Heat and Mass Transfer, 47, 385-393.

Sara, O.N., Pekdemir, T., Yapıc1, S., Yılmaz, M. 2001. Enhancement of Heat Transfer from a Flat Surface in a Channel Flow by Attachment of Rectengular Blocks, International Journal of Energy Research, 25, 563-576.

Uğurlubilek, N., Uralcan, İ.Y., 2011. Helisel Türbülatörlerin Is1 Geçişine Etkisinin Sayısal İncelenmesi. Eskişehir Osmangazi Üniversitesi Mühendislik Mimarlık Fakültesi Dergisi, XXIV, 2.

Eiamsa-ard, S., Thianpong, C., Eiamsa-ard, P., Promvonge, P. 2009. Convective heat transfer in a circular tube with shortlength twisted tape insert, International Communications in Heat and Mass Transfer, 36, 365-371.

Eiamsa-ard, S., Thianpong, C, Eiamsa-ard,P. 2010. Turbulent heat transfer enhancement by counter/co-swirling flow in a tube fitted with twin twisted tapes, Experimental Thermal and Fluid Science, 34, 53-62.

Karagoz, S., Afshari, F., Yildirim, O., and Comakli, O. 2017. Experimental and numerical investigation of the cylindrical blade tube inserts effect on the heat transfer enhancement in the horizantal pipe exchangers. Heat and Mass Transfer, 53(9), 2769-2784

Karagoz, S. 2015. Investigation of thermal performances of "S-shaped" enhancement elements by response surface methodology. Heat and Mass Transfer, 51(2), 251-263.

Zhou, D.W., and Lee, S-J. 2004. Heat Transfer Enhancement of Impinging Jets Using Mesh Screens, International Journal of Heat and Mass Transfer, 47, 2097-2108.

Ho, C.D., Yeh, C.W., Hsieh, S.M., 2005. Improvement in Device Performance of Multipas Flat-Plate Solar Air Heaters with External Recycle, Renewable Energy, 30, 1601-1621, 
Chen, W. L., Wong, K.L., Huang, C.T., 2006. "A parametric study on the laminar flow in an alternating horizontal or vertical oval cross-section pipe with computational fluid dynamics", International Journal of Heat and Mass Transfer, 49: 287-296.

MEB/Hayat Boyu Öğrenme Genel Müdürlüğü(hbogm), Ünite 5, https://hbogm.meb.gov.tr/MTAO/2Elekt rikBilgisi/unite05.pdf, Son erişim tarihi: 03.12.2018

MEB/Hayat Boyu Öğrenme Genel Müdürlüğü(hbogm), Ünite 6 ,
https://hbogm.meb.gov.tr/MTAO/1Elekt roteknik/unite6.pdf, Son erişim tarihi: 03.12.2018

Iprocessmart.

2017.

https://www.iprocessmart.com/techsmart 13-phase_equations.htm, Son Erişim Tarihi: 03.12.2018

Kahraman N., Sekmen, U., Çeper, B., Akansu, O. 2008. Boru İçi Akışlarda Türbülatörlerin Is1 Transferine Olan Etkisinin Sayısal İncelenmesi. Isı Bilimi ve Tekniği Dergisi, 28, 2, 51-59 